\title{
IKON TRADISI BA'DO KATUPAT SEBAGAI REFLEKSI KEBUDAYAAN MASYARAKAT JATON DI SULAWESI UTARA
}

\author{
Kinayati Djojosuroto \\ FBS Universitas Negeri Manado \\ email: kinayati_dj@yahoo.com
}

\begin{abstract}
Ba'do Katupat celebration is a tradition of Jawa Tondano (Jaton) village hold annually. It has a deep meaning to strengthen the relationship, forgive each other, as well as be grateful for the success of fasting for the whole month. No wonder the celebration is always crowded with thousands of people from different areas, ages and beliefs, and carried out for the whole day. Ba'do Ketupat is an inherited tradition from Diponegoro, Kiai Mojo, and his followers. This Javanese tradition heritage can be found in Tondano, Minahasa as a ceremonial event held annually by people in Jaton village one week after Eid Ba'do Ketupat contains cultural values that include local and cultural values, as the icon and identity of Jaton in Minahasa, as well as the acculturation resulting in solidarity and tolerance. This culture unites the minority of Jaton people with the majority of Minahasa people. The religious ritual performed by Jaton people and other Muslim accomplishes religious obligations in order to increase devotion towards Allah SWT and not to create difference.

Perayaan Ba'do Katupat merupakan tradisi kampung Jawa Tondano yang dilaksanakan setiap tahun. Acara ini memiliki makna yang mendalam yaitu untuk memperkokoh tali silaturahim, bermaaf-maafan, sekaligus ucapan syukur atas keberhasilan menjalankan ibadah puasa sebulan lamanya. Tak heran perayaan tersebut selalu dipadati ribuan masyarakat dari berbagai daerah, usia dan keyakinan dan berlangsung sejak pagi hingga malam hari. Ba'do Katupat merupakan tradisi yang diwariskan Diponegoro, Kiai Mojo dan pengikut pengikutnya. Tradisi ini adalah warisan tradisi Jawa yang ada di Tondano Minahasa dan menjadi acara seremonial yang setiap tahun diselenggarakan
\end{abstract}


warga di Kampung Jaton setelah lewat satu minggu lebaran. Ba'do Katupat mengandung nilai-nilai budaya yang mencakup kearifan lokal dan kearifan budaya Jaton, sebagai ikon dan identitas warga Jaton di Minahasa, serta sebagai akulturasi budaya sehingga terjadi solidaritas dan toleransi. Budaya tersebut mempersatukan penduduk minoritas Jaton dengan penduduk mayoritas Minahasa. Ritual keagamaan yang dilakukan oleh orang Jaton maupun Muslim yang lain merupakan pelaksanaan kewajiban agama dalam upaya meningkatkan ketakwaan kepada Allah SWT dan bukan menciptakan perbedaan.

Keywords: Ba'do Katupat, Tradition icon, Jaton

\section{Pendahuluan}

Keberadaan Pangeran Diponegoro, Kiai Modjo dan para pengikutnya di Sulawesi Utara tahun 1830 tidak terlepas dari peristiwa perlawanan rakyat di Jawa dalam menentang kolonialisme Belanda. Dalam sejarah Bangsa Indonesia dikenal dengan Perang Diponegoro (1825-1830) atau dalam literatur asing disebut Perang Jawa (Java war). Dalam perang ini, Kiai Modjo sangat berjasa karena beliau menyambut seruan Pangeran Diponegoro untuk membantu dan menggerakkan para pengikutnya untuk berperang melawan Kolonial Belanda. Kiai Modjo selain sebagai seorang ulama dan penasihat spiritual Pangeran Diponegoro, juga berperan sebagai seorang panglima perang (Babcock, 1981: 5).

$B a$ 'do Katupat merupakan tradisi yang diwariskan Diponegoro, Kiai Mojo dan pengikut-pengikutnya. Tradisi ini adalah warisan tradisi Jawa yang ada di Tondano Minahasa. Ba'do Katupat adalah acara seremonial yang setiap tahun diselenggarakan warga di Kampung Jawa Tondano (disingkat Jaton), setelah lewat satu minggu Hari Raya Idul Fitri. Tradisi Ba'do Katupat merupakan Budaya Jaton yang memiliki kekhasan tersendiri. Merayakan $B a^{\prime} d o$ Katupat bertujuan untuk mempererat tali silaturahim antara sesama warga Jaton, penduduk asli Jaton maupun pendatang dari luar daerah. Selain itu para sesepuh dan generasi muda mencoba menelusuri garis keturunan atau silsilah yang hilang antara warga Jaton dan keturunannya di daerah lain. Biasanya Ba'do Katupat (Lebaran Ketupat) lebih ramai dari pada Ba'do Idul Fitri karena Ba'do Katupat merupakan ajang pertemuan antara masyarakat asli Jaton dengan warga pendatang. Acara ini dijadikan ajang untuk memamerkan bentuk ketupat dan lauknya, kue-kue, serta pakaian baru. Tradisi Ba'do Katupat Jaton, merupakan ikon dan identitas tersendiri. Setiap keluarga menerima siapa saja yang datang bertamu, hampir sama dengan acara open house seluruh kampung bagi siapa saja yang datang, baik muslim maupun non muslim. 
Perayaan Ba'do Katupat ini, sudah menjadi tradisi warga kampung Jaton yang dilaksanakan pada setiap tahun. Bagi masyarakat kampung Jaton, acara seperti ini memiliki makna yang mendalam, yaitu untuk memperkokoh hubungan tali silaturahim, bermaaf-maafan, sekaligus ucapan syukur atas keberhasilan manjalankan ibadah puasa sebulan lamanya. Tidak heran pada perayaan tersebut, selalu dipadati oleh ribuan masyarakat dari berbagai daerah, muslim maupun non muslim, tua-muda, sejak pagi hingga malam hari.

\section{Asal Usul Ba'do Ketupat}

Tradisi Ba'do Katupat dibawa oleh Kiai Modjo dan para pengikutnya yang diasingkan oleh pemerintah Kolonial Belanda pada akhir 1829 M dan tiba di Tondano pada awal 1830 M. Mereka berjumlah 63 orang yang semuanya adalah kaum pria. Dengan rasa solidaritas dan kesetiakawanan yang tinggi, mereka diterima oleh Kepala Walak Tondano dan Tonsea, yaitu Opo' Rumbayan dan Opo' Sangari. Kedua Kepala Walak ini merupakan Kepala Wilayah (Kepala Daerah) yang didiami oleh sub etnik Tondano dan sub etnik Tonsea. Pada waktu itu daerah Minahasa (Tanah Minahasa) diperintah oleh empat Kepala Walak, yaitu kepala Walak Tondano, Tonsea, Tomohon dan Tontemboan, yang masing-masing memerintah sub etnik Tondano (Toulour), Tonsea, Tomohon (Tombulu) dan Tontemboan yang dianggap sebagai penduduk asli Minahasa (Tumenggung, 1980: 71).

Kiai Modjo dan pengikutnya ditempatkan (diberi pemukiman) dalam wilayah perbatasan antara Tondano dan Tonsea. Mereka membangun perkampungan yang dinamakan Kampung Jawa. Dalam kehidupan selanjutnya mereka diizinkan oleh Kepala Walak Tonsea dan Tondano untuk menikahi gadis-gadis setempat (Minahasa). Dalam hubungan ini seorang missionaris dari Belanda mengatakan: "Zich een familie ven den vrowen tenement van ditland zoo hune eigene vrowen hen nit gevalgd" (Graafland, 1898: 72). Artinya, mereka membentuk keluarga dengan menikahi para wanita dari daerah ini, karena mereka tidak membawa serta para istrinya. Dengan terjadinya pernikahan ini maka sesuai dengan adat yang berlaku pada waktu itu, Kepala Walak Tonsea dan Tondano menghadiahkan tanah-tanah pertanian sebagai maskawin kepada keluarga baru itu untuk menjadi sumber mata pencaharian bagi kehidupan mereka. Tanah-tanah pertanian itu terletak dalam wilayah perbatasan antara Tonsea lama dan Tondano yang meliputi wilayah: Pamburingen, Kulo, Sasaran, Tegalrejo dan Kampung Jawa, Bacek, Wunong, Komplek Tanah Pekuburan Kiai Modjo, Tondata, Marawas, Wilouwan, Lewang, Rombek 
Tawi, Makawaimbeng, Kampung Baru, Rano Tua, Pertandingan, Winetin dan Klisapun (Yayasan Kiai Modjo, 1977: 11).

Mereka kemudian menanam padi, ketan, jagung, kacang tanah, kedelai, sayur-mayur, buah-buahan, kelapa, kopi, cengkeh dan rempah-rempah, kemudian hasil tanaman ini mereka jual dan dijadikan berbagai jenis makanan seperti: Ketupat, Jenang, Serabi, Wedang Serbat, Apem, Mendot, Gelali, Aluwa, Opor, Gerontol, Semor, Gudek, Sego Gebuli, Jenang Abang, Biji-biji, Cipik, Apem, dan lain-lain. Jenis-jenis kue dan masakan lain-lain, selain dikonsumsi sendiri, juga dijual kepada warga sekitar di Tondano. Dengan demikian mereka telah memperkenalkan budaya Jaton dalam bidang pertanian, kuliner, dan berbagai profesi kerajinan, seperti: tukang jahit, tukang pedati, tukang besi, belantek (dagang) dan lain-lain. Dalam hubungan ini Graafland mengemukakan:

"Menurut peradaban bungsa, mereka sudah memiliki peradaban yang lebih tinggi dari pada suku Minahasa zaman dahulu, seperti dalam kerajinan industri. Karena itui mereka bukan saja mengelola sawah mereka sendiri, tetapi juga mereka menjadi guru orang-onang Tondano dalam mengelola sawah" (Graafland, 1898: 272-273).

Khususnya mengenai keterampilan membuat ketupat yang dibuat dari janur adalah tradisi yang berasal dari Kraton Jogyakarta dan Solo, kemudian tradisi ini mereka wujudkan, kembangkan, dan wariskan kepada keturunannya sampai sekarang. Ketupat adalah sejenis makanan yang berisi beras atau ketan, lalu disajikan pada hari raya ketupat (Ba'do Katupat).

\section{Ba'do Ketupat sebagai Ikon Jaton di Minahasa}

Kata ba'do berasal dari bahasa Arab ba'du yang berarti sesudah (selesai). Maksudnya sesudah dilaksanakan ibadah puasa pada bulan Ramadhan. Adanya pengaruh ejaan bahasa Jawa maka kata $b a^{\prime} d u$ menjadi $b a$ 'do . Jadi, Hari Raya Idul Fitri yang dilakukan sesudah ibadah puasa itu, oleh masyarakat Jawa Tondano (Jaton) disebut "Ba'do Katupat", yang artinya lebaran setelah selesai melaksanakan ibadah puasa wajib Ramadhan dan puasa sunnah satu minggu diawal bulan Syawal (Tumenggung,1984: 11).

Hari Raya Ketupat disebut Ba'do Katupat, yang artinya sudah selesai melaksanakan ibadah puasa satu bulan Ramadhan dan sudah selesai melaksanakan ibadah puasa sunnah enam hari di Bulan Syawal. Untuk kemenangan itu diadakan hari raya ketupat. Seperti diketahui dalam ajaran agama Islam, puasa Bulan Ramadhan, sholat Idul Fitri dan puasa sunnah Syawal selama enam hari, merupakan satu paket yang tidak dapat dipisahkan. Oleh masyarakat Jaton puasa sunnah yang dilakukan selama enam hari itu, 
dinamakan Poso Sawal. Puasa ini dilakukan untuk mendapat tambahan pahala dari Allah SWT. Akan tetapi bila tidak dilaksanakan, tidak akan mendapat tambahan pahalanya. Puasa ini biasanya dilakukan oleh orang-orang yang sudah melakukan ibadah haji dan orang-onang tua yang ikhlas rnelakukannya, karena hukumnya adalah sunnah. Warga Jaton menyebutnya sebagai Poso Sunnat. Namun saat ini sudah banyak generasi muda yang suka menjalankan puasa sunnah. Selesai dengan ibadah ini, ditutup dengan Ba'do Katupat (kenduri ketupat) di masjid dan dilanjutkan dengan saling bermaaf-maafan lahir batin antara satu dengan yang lain.

Sementara itu, kata katupat berasal dari Bahasa Indonesia (Melayu) yakni ketupat. Karena pengaruh Bahasa Tondano kata ketupat menjadi katupat yang berarti nasi yang dimasak dalam anyaman janur kelapa. Ketupat adalah makanan yang dibuat dari beras yang dimasukkan dalam anyaman atau dibungkus dalam kantong anyaman pucuk daun kelapa muda yang kantongnya berbentuk segi empat dan sebagainya, kemudian ditanak (direbus), dimakan sebagai pengganti nasi (KBBI, 1966: 497). Bagi masyarakat Jaton, katupat dikenal dua macam yaitu ketupat biasa yang dibuat dari beras biasa (katupat karengan) yang direbus dengan air biasa dan ketupat ketan yang dibuat dari beras ketan (katupat ketan) yang direbus dengan santan/santen. Katupat karengan, direbus seperti menanak nasi dan biasanya dimakan dengan sambel goreng kering atau sambel goreng santan. Sedangkan katupat ketan, direbus dengan santan kelapa bercampur bumbu jahe, kunyit, sere dan garam, sehingga rasanya sangat gurih dan dapat dimakan tanpa lauk. Katupat ketan inilah yang banyak digemari masyarakat luar Jaton yang bertamu. Cara menyajikan, kedua macam ketupat itu dibelah (dipotong) terlebih dahulu menjadi dua atau empat bagian agar mudah disantap, lalu disajikan tidak terlepas dari janurnya (janor).

\section{Kearifan lokal}

Kearifan lokal, atau dalam bahasa asing sering juga dikonsepsikan sebagai kebijaksanaan setempat "local wisdom" atau pengetahuan setempat "local knowledge" atau kecerdasan setempat "local genious", merupakan pandangan hidup, ilmu pengetahuan, dan berbagai strategi kehidupan yang berwujud aktivitas yang dilakukan oleh masyarakat setempat dalam menjawab berbagai masalah dalam pemenuhan kebutuhan mereka. Kearifan lokal di berbagai daerah di seluruh Nusantara merupakan kekayaan budaya yang perlu diangkat kepermukaan sebagai bentuk jati diri bangsa. Menteri Kebudayaan dan Pariwisata, Jero 
Wacik, dalam sambutannya pada Simposium Internasional IX Pernaskahan Nusantara di Baubau, tanggal 5 Agustus 2005 mengatakan, kearifan lokal yang terdapat di berbagai daerah di Nusantara, seharusnya diangkat dan dihargai sebagai salah satu acuan nilai dan norma untuk mengatasi berbagai persoalan yang dihadapi bangsa Indonesia saat ini. Mengangkat tradisi Ba'do Katupat merupakan suatu kearifan lokal di Jaton (Arbie, 2011: 2).

Untuk melestarikan budaya Jaton, biasanya juga dengan cara memasak kue-kue yang resepnya merupakan kombinasi resep Jawa dan resep Tondano, dan inilan yang menjadi masakan khas Jaton. Kue- kue ini jarang ditemukan di tempat lain, diantaranya: Katupat Ketan, Jenang, Jenang Abang, Mendot, Lampu-lampu, Gawo'-gawo', Bungkusan, Sinenggor, Contongan, Ginonso, Gandos, Roti Bantal, Roti Goraka, Apem dan masih banyak lagi (Noviandi, 2011: 3).

\section{Kearifan Budaya}

Tradisi Ba'do Katupat juga termasuk dalam kearifan budaya. Kearifan budaya adalah energi potensial dari sistem pengetahuan kolektif masyarakat untuk hidup di atas nilai-nilai yang membawa kelangsungan hidup yang memiliki peradaban; hidup damai, hidup rukun, hidup bermoral, hidup saling asih, asah, dan asuh, hidup dalam keragaman, hidup penuh maaf dan pengertian, hidup toleran dan jembar hati, hidup harmoni dengan lingkungan, hidup dengan orientasi nilai-nilai yang membawa pada pencerahan, hidup untuk menyelesaikan persoalan-persoalan berdasarkan mozaik nalar kolektif sendiri. Kearifan seperti itu tumbuh dari dalam lubuk hati masyarakat sendiri. Itulah bagian terdalam dari kearifan kultur lokal (Koentjaraningrat, 1993: 27).

Merayakan Ba'do Katupat mempunyai tujuan utama yakni mempererat tali kekeluargaan, tali silaturahim antara sesama warga Jaton baik di dalam maupun di luar daerah (perantau), serta warga Jaton dengan masyarakat umum. Selain itu para sesepuh dan generasi muda mencoba mengangkat lagi garis keturunan yang hilang atau putus antara warga Jaton dan keturunannya di daerah lain. Biasanya Ba'do Katupat lebih ramai dari pada Ba'do Idil Fitri. $B a$ 'do Katupat merupakan ajang memamerkan kemahiran membuat macammacam bentuk ketupat, seperti: katupat panggang, katupat luar, katupat jantong, katupat bawang, dan katupat roa. Selain itu, Ba'do Katupat juga merupakan ajang memamerkan jenis-jenis makanan, kue-kue, dan baju baru.

Tradisi Ba'do Katupat Jaton, merupakan ikon dan identitas tersendiri. Setiap keluarga menerima siapa saja yang datang bertamu, seperti acara open house dari seluruh kampung untuk siapa saja yang datang. Perayaan Ba'do 
ketupat ini, sudah menjadi tradisi warga kampung Jaton yang dilaksanakan pada setiap tahunnya, sejak dahulu kala yang diwariskan dari nenek moyang atau leluhur mereka. Oleh warga kampung Jawa Tondano yang lebih akrab disapa Jaton, acara seperti ini memiliki makna yang mendalam yaitu selain memperkokoh hubungan tali silaturahim sekaligus ucapan syukur atas keberhasilan manjalankan ibadah puasa sebulan lamanya, juga mempererat kerukunan antar umat beragama di Tondano khususnya bahkan Minahasa pada umumnya. Tidak heran di perayaan tersebut, selalu dipadati ribuan masyarakat dari berbagai daerah, mulai pagi hari hingga malam hari, bahkan dihadiri gubernur, kepala daerah atau camat.

\section{Kearifan Lokal Yang Terkandung dalam Ketupat}

1. Makna Persatuan (Ukhuwah Islamiyah)

Seperti sudah dijelaskan di atas bahwa ba'do dan ba'do katupat merupakan satu paket sebagaimana dengan puasa Ramadhan dan puasa sunnah (poso syawal). Ba'do katupat itu dianggap sebagai penutup acara saling memaafkan lahir batin (halalbi halal) antara sesama warga Jaton, sehingga hal ini merupakan wadah pengikat rasa persaudaraan, persatuan dan kesatuan dikaitkan dengan ikatan persatuan beras dalam ketupat yang sudah dimasak. Dengan demikian ikatan persatuan (ukhuwah islamiyah) itu dilambangkan dengan ikatan penyatuan beras dalam ketupat. Ikatan ini pula diwujudkan dalam musyawarah dan mufakat untuk membicarakan berbagai permasalahan yang timbul dalam masyarakat Jaton. Musyawarah diadakan dalam mesjid pada hari ba'do katupat, dimulai pukul 08.00 pagi sampai pada pukul 12.00 siang, lalu ditutup dengan kenduri ketupat (kenduren ketupat) dan berakhir dengan sholat Dzuhur berjama'ah.

\section{Makna Religius}

Ba'do Katupat merupakan tradisi Kraton Jogyakarta dan Solo yang dibawa oleh Kiai Modjo dan pegikutnya. Kedua kraton ini menjadi pusat kegiatan mendalami diri (mengenal diri) sebelum mengenal Allah SWT (ma'rifatullah). Ilmu mengenal diri ini disebut Ilmu Tarekat atau Ilmu Tasawwuf. Orang-orang yang ahli ilmu ini dinamakan, salah satu ilmu tarekat yang diwariskan oleh Kiai Modjo dan pengikutnya kepada keturunannya adalah Ngelmu Tarekat Sotorio (jalan lurus). Inti dari ilmu tarekat ini adalah usaha untuk mempersatukan kembali unsur jasad dan unsur roh manusia sebagaimana asal kejadiannya. Untuk itu kedua unsur ini (lahir dan batin) hendaknya 
disucikan dengan cara beramal yang benar agar bisa menghadap kepada Allah Yang Maha Suci. Dalam kaitannya dengan makna ketupat, terutama katupat jantong (ketupat yang dibuat berbentuk jantung manusia) yang dianggap sebagai ketupat asli, artinya ketupat yang pertama kali diciptakan oleh para leluhur. Katupat jantong (jantung) ini dilambangkan sebagai jantung manusia yang merupakan motor penggerak hidup untuk mengabdi/ beribadah hanya kepada Allah SWT saja. Sedangkan penyatuan ribuan butir beras dalam ketupat, selain dilambangkan sebagai persatuan, juga sebagai lambang penyatuan antara jasad dan roh. Usaha merebus (menggodok) beras dalam ketupat agar menjadi masak dan menyatu, mengandung makna usaha atau jalan (tarekat) yang harus ditempuh dengan perjuangan berat agar bisa berhasil disatukan. Sedangkan kulit pembungkus ketupat (janur) dianggap sebagai syariat agama (Rukun Islam) yang wajib diamalkan untuk bisa menempuh pengalaman yang lebih tinggi (Wawancara dengan tokoh Jaton tanggal 5 Juli 2000).

Dengan demikian ketupat itu mengandung makna tasawwuf atau tarekat sebagai berikut:

1. Kulit atau janur pembungkus merupakan syariat agama Islam.

2. Cara memasukkan beras (ukuran), menyiapkan bumbunya dan usaha merebus ketupat, merupakan usaha/ tarekat (jalan).

3. Ketupat yang sudah masak menjadi nasi (penyatuan beras), merupakan hakikat (tujuan akhir yang benar).

4. Menyantap ketupat yang enak dan gurih, merupakan ma'rifat atau pengenalan (Tumenggung, 1984: 12).

Oleh karena itu, para leluhur (Kiai Modjo dan pengikutnya) selalu berpesan kepada anak, cucu, dan cicitnya agar bisa membuat ketupat jantung (jantong) apabila menginginkan keselamatan hidup di dunia maupun di akhirat. Hal ini mengandung makna bahwa hendaknya keturunan mereka mempelajari dan mengamalkan ilmu tarekat (tasawwuf) untuk bisa mengenal diri agar selamat hidup di dunia dan di akhirat. Mengenal diri dimaksudkan bahwa hendaklah setiap insan (manusia) mengetahui siapa dirinya yang sebenarnya, dari mana asal kejadiannya dan kemana akhir tempat kembalinya. Inilah yang dimaksud dengan ungkapan yang diterima atau diwariskan kepada masyarakat Jaton, yaitu "wero kawitan eleng pungkasan" (Tumenggung, 1984: 13).

Aspek-Aspek Penghambat

el Harakah Vol.15 No.2 Tahun 2013 
Hubungan dan kerjasama yang harmonis telah dijalani sebelumnya oleh para pendiri Kampung Jawa dengan penduduk sekitarnya. Dalam perkembangannya hubungan tersebut kadang-kadang terganggu, karena renggangnya ikatan kekeluargaan, kuatnya pengaruh agama dan budaya antara kedua kelompok masyarakat tersebut. Sikap kolonial Belanda telah melahirkan perbedaan antara kedua kelompok masyarakat ini, memperlakukan mereka (orang Kampung Jawa) sebagai orang buangan karena dianggap sebagai pemberontak terhadap pemerintah Kolonial yang sah sehingga pantas dibuang jauh dari daerah asalnya. Hal ini sebagaimana terlihat dalam catatan seorang Missionaris dari Belanda yang pernah bertugas di Minahasa, bahwa orang Kampung Jawa adalah orang-orang buangan yang menyesali perbuatan yang telah dilakukannya sebagai pemberontak, diperlakukan sebagai orang buangan (Manuhutu, 1976: 30)

Beberapa tradisi dalam keagamaan (hadrat dan selametan) serta hal-hal lain yang berkaitan dengan kewajiban dalam agama tetap dipertahankan oleh para pendiri Kampung Jawa dan generasi-generasi selanjutnya. Tradisi inilah yang membuat orang Kampung Jawa tetap berbeda dengan orang Minahasa di sekitar pemukimannya yang beragama Kristen. Ungkapan yang sering digunakan untuk menunjukkan identitas minoritas Jaton adalah tou nyowo (orang Jawa) atau tou selam (orang Islam).

Orang Kampung Jaton juga menjadi sasaran dan korban kekerasan dari berbagai peristiwa sebagai reaksi terhadap kebijaksanaan pemerintah pusat yang sebagian besar adalah orang Jawa. Hal ini dinilai kurang adil. Contoh tindakan PPK (Pasukan Pembela Keadilan) dan Permesta, yang menyamakan orang Kampung Jawa Tondano dengan orang Jawa (tou nyowo) sehingga pada tahun 1958 Kampung Jawa direncanakan dibumihanguskan. Kapala kampung/ Hukum Tua (Lurah ) Jaton, Hamdani Tumenggung Zees, diculik dan dibunuh tentara Permesta dan mayatnya tak tentu dimana rimbanya. Beberapa sesepuh Jaton juga mengalami hal yang sama seperti Lurah Hamdani. Untunglah tentara pusat dari pulau Jawa cepat tiba dan menghalangi rencana pembumihangusan kampung Jaton oleh Permesta. Padahal tidak ada relevansinya, bila diidentikkan dengan agama dan etnik Jaton (Latief, 1972: 15).

\section{Upaya Menjalin Integrasi}

Perlu dikembangkan dan digalakkan terus aspek-aspek pendorong integrasi antara kedua belah pihak yang berakulturasi berdasarkan ikatan kekeluargaan yang telah dijalin melalui pernikahan. Saling menunjang dalam pemenuhan 
kebutuhan hidup telah dirintis oleh para pendiri Kampung Jawa. Orang Minahasa harus memahami bahwa kegiatan keagamaan yang dilakukan oleh orang Jaton maupun penganut agama Islam yang lain di daerahnya adalah sebagai pelaksanaan kewajiban agama dalam upaya meningkatkan ketakwaan kepada Allah Yang Maha Kuasa dan bukan menciptakan perbedaan.

Orang Minahasa dan orang Jaton harus menyadari bahwa perbedaan yang melekat di antara mereka diciptakan oleh kolonial Belanda dan Missionaris untuk mencapai tujuannya. Penganut salah satu agama di suatu daerah adalah sebagai bagian dari penganut salah satu agama yang ada di Indonesia bahkan dunia. Tidak perlu menyamakan mereka dengan orang Jawa sebagaimana pengakuan orang Jaton, secara lokal bahwa mereka adalah orang Tondano atau saya orang Tondano atau Nyaku Toundano (Tumenggung, 1984: 5).

Kegiatan arisan dan "rukun" kekeluargaan yang melibatkan orang Jaton dan Minahasa perlu digalakkan terus karena sudah dirintis para leluhur, kemudian dikembangkan pula dalam kegiatan seperti kesenian dan olah raga serta mapalus ( kerja gotong royong bergilir) yang telah dikenal secara luas di Minahasa.

\section{Simpulan}

Tradisi Ba'do Katupat merupakan ikon dan identitas budaya Jaton di Sulawesi Utara karena Ba'do Katupat merupakan tradisi yang mengandung kearifan lokal. Refleksi budaya Jaton dapat diterima oleh etnik mayoritas Minahasa. Dalam hal ini, telah terjadi akulturasi antara budaya Jaton dan budaya Minahasa sehingga tercipta solidaritas, kesetiakawanan dan toleransi.

Ba'do Katupat merupakan budaya yang telah mempersatukan penduduk minoritas Jaton dengan penduduk mayoritas Minahasa. Saling berkunjung dan saling menghargai, telah menjadi kerukunan di Minahasa pada umumnya dan Tondano pada khususnya.

Ritual keagamaan yang dilakukan oleh orang Jaton maupun penganut agama Islam yang lain merupakan pelaksanaan kewajiban agama dalam upaya meningkatkan ketaqwaan kepada Allah SWT dan bukan menciptakan perbedaan.

\section{Daftar Pustaka}

Arbie, Bakri. http://jatonindonesia.net/muka (diunduh, 25 januari 2011)

Babcock, Tim. 1981. Muslim Minahasaus with Roots in Java; The people of Kampung Jawa Tondano dalam Indonesia no. 32, tahun 1981, USA: 
Cornel University.

Graafland, N. 1991. Minahasa: Negeri, Rakyat dan Budayanya. Jakarta: PT Pustaka Utama Grafiti.

Koentjaraningrat. Masalah Kesukubangsaaan dan Integrasi Nasional. Jakarta: UI Press, 1993.

Latief, Hasna, N. 1972. Suatu Tinjauan Historis Tentang Keturunan Kiai Modjo di Minahasa. FKIS/IKIP Manado,

Manuhutu, E. 1976. Timbulnya Kombinasi yang Harmonis antara Unsur-Unsur Kebudayaan Minahasa dan Jawa sejak Abad XV, dalam Yapenra, nomor II tahun III Pebruari.

Noviandi, Kiki Rizki. www.gorontalofamily.org (diunduh,25 januari 2011)

Tumenggung, Sis, M. 1984. Mapalus Orang-Orang jawa Tondano Kecamatan Tondano Kabupaten Minahasa. Fakultas Sastra UNSRAT,

Yayasan Kiai Modjo. 1977. Pengikut-Pengikut Pangeran Diponegoro dan Kiai Modjo di Sulawesi Utara, Manado: Yayasan Kiai Modjo.

Lampiran
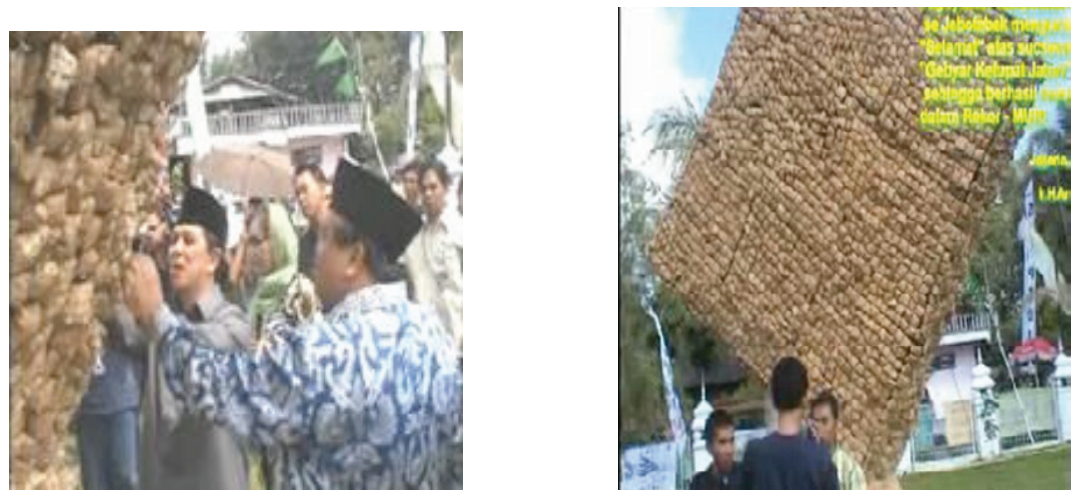

Ketupat Raksasa Jaton yang masuk dalam Rekor MURI

(Noviandi, www.gorontalofamily.org (diunduh, 25 januari 2011) 


\section{PEDOMAN UMUM}

1. Artikel yang ditulis untuk Jurnal el-Harakah adalah meliputi hasil pemikiran dan hasil penelitian di bidang Budaya Islam. Naskah diketik dengan huruf Times New Roman, ukuran 12 pts, dengan spasi 1,5 spasi, dicetak pada kertas A4 sepanjang maksimum 20 halaman, dan diserahkan dalam bentuk print-out sebanyak 3 eksemplar beserta filenya. Berkas (file) dibuat dengan Microsoft Word (ekstensi RTF).

2. Nama penulis dicantumkan tanpa gelar akademik dan ditempatkan di bawah judul artikel. Penulis dianjurkan mencantumkan nama lembaga, telepon, dan e-mail untuk memudahkan komunikasi.

3. Seluruh judul bagian dan sub-bagian dicetak tebal (bold), dan tidak menggunakan angka/nomor pada judul bagian.:

4. Sistematika penulisan artikel hasil pemikiran adalah: judul; nama penulis (tanpa gelar akademik); abstrak (maksimal 200 kata); kata kunci; pendahuluan (tanpa judul) yang berisi latar belakang dan tujuan atau ruang lingkup tulisan; bahasan utama (dapat dibagi ke dalam beberapa sub-bagian); penutup atau simpulan; daftar pustaka (hanya memuat sumber-sumber yang dirujuk).

5. Sumber pustaka diutamakan adalah sumber-sumber primer berupa laporan penelitian Skripsi, Tesis, Disertasi, atau artikel-artikel penelitian dalam jurnal dan majalah ilmiah.

7. Perujukan dan pengutipan menggunakan teknik rujukan berkurung (nama, tahun: halaman). Pencantuman sumber pada kutipan langsung hendaknya disertai keterangan tentang nomor halaman tempat asal kutipan. Contoh: (Kaelan, 2005: 47).

8. Daftar Pustaka disusun diurutkan secara alfabetis dan kronologis. 


\section{PENULISAN DAFTAR PUSTAKA}

\section{Buku}

Nama pengarang [atau editor]. Tahun terbit. Judul Buku. Tempat terbit: Nama penerbit.

\section{- Buku dengan Pengarang}

Abdullah, Amin. 2006. Islamic Studies di Perguruan Tinggi: Pendekatan Integratif dan Interkonektif. Yogyakarta: Pustaka Pelajar.

- Buku dengan Lembaga atau Organisasi sebagai Pengarang

[Depdikbud] Departemen Pendidikan dan Kebudayaan, Pusat Pembinaan dan Pengembangan Bahasa. 2010. Kamus Besar Bahasa Indonesia. Ed ke-3. Jakarta: Balai Pustaka.

[Fsaintek UIN Maliki] Fakultas Sains dan Teknologi, Universitas Islam Negeri Maulana Malik Ibrahim. 2009. Pedoman Penulisan Tugas Akhir. Malang: Fsaintek UIN Maliki.

\section{- Buku terjemahan:}

Wood, Alan dan Grant, Ted. 1995. Revolusi Berpikir dalam Ilmu Pengetahuan Modern. Terjemahan oleh Rafiq N. 2006. Yogyakarta: IRE Press.

\section{- Buku kumpulan artikel:}

Irawan, Irma dan Supriyanto, Andi [Eds]. 1999. Jurnalistik Kontemporer (Edisi ke-2, cetakan ke-1). Bandung: Salsabila Press.

\section{- Artikel dalam buku kumpulan artikel:}

Geertz, Clifford. 1999. Religion as a Cultural System. Dalam Garry E. Kessler, Philoshophy of Religion: Towards A Global Perspektif [hlm 11-12]. Belmont: Wadsworth Publishing Company.

\section{Surat Kabar}

Nama pengarang. Tanggal bulan tahun terbit. Judul. Nama surat kabar. Nomor halaman (nomor kolom). 
Kuncoro, Toha. 1 Desember, 2007. Pergulatan Menuju Perdamaian Palestina. Jawa Pos: 6 (kolom 2-5).

\section{- Tulisan berita dalam koran (tanpa nama pengarang):}

Surya. 31 Desember 2008. KPK Pelototi Dana Yayasan Instansi Negara. Halaman 3.

\section{Dokumen Resmi}

[Depdiknas] Departemen Pendidikan Nasional. 2002. Keputusan Menteri Pendidikan Nasional Republik Indonesia Nomer 045/U/2002 tentang Kurikulum Inti Pendidikan Tinggi. Jakarta: Depdiknas.

\section{Makalah seminar, lokakarya, penataran, pelatihan, workshop:}

Rahardjo, Mudjia. 2007. Metodologi Penulisan Artikel Jurnal Ilmiah. Makalah disajikan dalam Workshop Pelatihan Mutu Jurnal Ilmiah. Malang: Unit Informasi dan Publikasi (Infopub) Universitas Islam Negeri Malang. Tanggal 7-12 Desember.

\section{Acuan Melalui Internet}

\section{- Artikel dari Publikasi Eletronik}

Nama pengarang. Tahun penerbitan. Judul artikel. Nama jurnal. Volume (nomor) halaman. [tipe media]. Ketersediaan. [Tanggal, bulan dan tahun akses].

Sukandana, I Made. 2009. Kebo-keboan dan Ider Bumi Suku Using: Potret Inklusifisme Islam di Masyarakat Using Banyuwangi. Jurnal el Harakah. Volume 13, Nomor 2: Tahun 2011 Hal.169196. http://Infopub.uin-malang/el harakah.

\section{- Abstrak dalam Jurnal Ilmiah}

Nama pengarang, Tahun penerbitan. Judul artikel. Nama jurnal. Volume (nomor): abstrak [tipe media]. Ketersediaan. [Tanggal, bulan, dan tahun akses].

Supriyatna, Endang. 2008. Kepercayaan Tradisional dan Ketakwaan 
Terhadap Tuhan Yang Maha Esa dalam Sistem Sosial Budaya Masyarakat Betawi di DKI Jakarta, (Jurnal Penelitian, Vol. 40, no.1, 607-640. http://Infopub.uin-malang/el harakah.

\section{- Bahan Diskusi}

Nama pengarang, Tahun penerbitan. Judul artikel. Nama forum diskusi. Ketersediaan. [Tanggal, bulan, dan tahun akses].

Afghani, Mohammad. 2010. Perkembangan Budaya Islam di Indonesia. Indonesia in Islamic Culture. Indonesianculture@yahoo.co.uk, [8 Juni 2010].

\section{- Pengiriman e-mail Pribadi}

Hayati, Elok Kamilah [eloksunardji@yahoo.com] 5 Mei 2010. Artikel untuk Jurnal el Harakah. E-mail kepada Jurnal el Harakah [elharakahjurnal@gmail.com]. 